\title{
Research on Esterification Reaction of Gutter Oil with Supported Acid Catalyst
}

\author{
Yanchao Zhao, Yun Wang, Maohui Qu, Feng Ouyang* \\ Environmental Science and Engineering Research Center \\ Shenzhen Graduate School, Harbin Institute of Technology \\ Shenzhen 518055, China \\ e-mail: zyanchaohit@163.com,febmeow@hotmail.com,qumh001@163.com, "ouyangfh@hit.edu.cn
}

\begin{abstract}
Active component $-\mathrm{SO}_{3} \mathrm{H}$ of activated carbon loaded catalyst is prepared by carbide sulfonation reaction between concentrated sulfuric acid and glycerol. And effects of different reaction conditions were studied on the basis of the reduce ratio of acid value after the esterification reaction occurred in fixed bed reactor. The experimental data show that the optimal catalyst preparation conditions are: mass ratio of glcerin and concentrated sulfuric acid on carbide sulfonation reaction is 1:2, activated carbon fully filled and less affected by the preparation temperature condition. The optimal reaction conditions are: molar ratio between gutter oil and methanol on esterification reaction is $1: 12.5$, reacting continuously by 5 hours and under the condition of reaction temperature of $65^{\circ} \mathrm{C}$. Under these conditions, the esterification ratecould reach as high as $\mathbf{9 6 . 0 \%}$.
\end{abstract}

Keywords-biodiesel; gutter oil; supported acid catalyst; esterification reaction

\section{INTRODUCTION}

Using gutter oil as edible oil for a long term could significantly increase the risk of human cancer [1] and huge profits were obtained by illegal vendors through the way of selling the gutter oil to victualing house. The dwindling of fossil energy and the global energy demand tension led to the rise of oil prices [2]. So countries around the world are looking for new kinds of energy to replace fossil energy such as wind, tidal energy and nuclear energy [3]. The process of preparation of biodiesel using gutter oil can solve the problem of the fossil energy crisis, the diseases caused by gutter oil and the environmental pollution from waste cooking oil at the same time [4].

The aim of this paper is to prepare an activated carbon loaded catalyst through the carbide sulfonation reaction between concentrated sulfuric acid and glycerol that can effectively catalyze esterification reaction between methanol and free fatty acids in the gutter oil. The preparation parameters, including preparation temperature, mass ratio of glcerin and sulfuric acid and the percent of loaded catalyst, such as reaction temperature, reaction time and molar ratio between gutter oil and methanol, were optimized to reach the highest esterification ratio of $96.0 \%$.

\section{Methodology}

\section{A. Catalyst preparation}

Carbonation reaction from glycerin and concentrated sulfuric acid was proceeded to prepare the activated carbon loaded acid catalyst. The detailed procedure was described as follows: Firstly, after glycerol was poured into a flask containing active carbon, the flask was continuously shaked until glycerin traces could be found nowhere. Secondly, the flask was placed in the oil bath heating for fixed time and heating temperature after the addition of a certain amount of concentrated sulfuric acid and shaked thoroughly. Thirdly, after washed with distilled water to $\mathrm{pH}$ of 7 , the catalyst was dried at $105^{\circ} \mathrm{C}$ for $18 \mathrm{~h}$.

\section{B. Catalytic activity}

Gutter oil used in the experiment was collected by Shenzhen Urban Wastes Disposal \& Recycling Center in this paper. The reaction temperature of fixed bed reactor was controlled by continuous external circulating water. The catalyst effect was represented as the esterification reaction ratio, which can be obtained by the ratio of the acid value reduced during the esterification reaction:

$$
\mathrm{C}=\frac{A-A_{i}}{A} \times 100 \%
$$

Where $\mathrm{C}$ is the esterification reaction ratio, $\mathrm{A}$ is the acid value of gutter before the esterification reaction, $A_{i}$ is the acid value of gutter after the esterification reaction.

\section{EMPIRICAL Results AND Discussion}

\section{A. Efffects of different preparation conditions}

1) Effects of preparation temperature on carbide sulfonation reaction. Figure1 shows the effects of preparation temperature in the range of $110^{\circ} \mathrm{C}$ to $140^{\circ} \mathrm{C}$ under the preparation conditions: the mass ratio of glcerin and sulfuric acid is $1: 4$, the percent of catalyst loaded is $60 \%$.The reaction conditions are: the molar ratio between gutter oil and methanol is $1: 10$, reaction temperature is $60^{\circ} \mathrm{C}$ and the reaction time is $3 \mathrm{~h}$. It can be seen that the esterification rate changed rarely with the increasing of temperature. The exothermic carbide sulfonation reaction 
produces lots of quality of heat that lead to a much higher temperature in the flask.

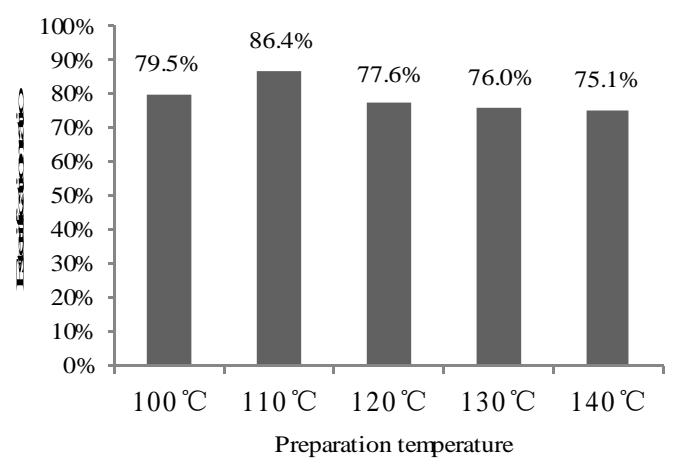

Figure 1. The effects of preparation temperature on the esterification reaction

2) Effects of mass ratio between glcerin and sulfuric acid on carbide sulfonation reaction. Figure2 shows the effects of mass ratio between glcerin and sulfuric acid on carbide sulfonation reaction within the range of $1: 2,1: 3,1: 4$, 1:5 and 1:6 under the preparation conditions: the preparation temperature is $110^{\circ} \mathrm{C}$, the percent of catalyst load is $60 \%$. The reaction conditions are: the molar ratio between gutter oil and methanol is $1: 10$, reaction temperature is $60^{\circ} \mathrm{C}$ and the reaction time is $3 \mathrm{~h}$.

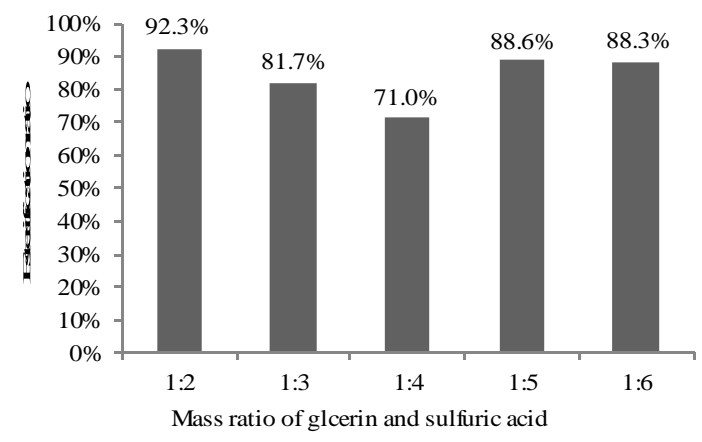

Figure 2. The effects of mass ratio of glcerin and sulfuric acid on the esterification reaction

Figure2 shows that the esterification ratio get the maximum value of $92.3 \%$ when mass ratio of glcerin and sulfuric acid is $1: 2$ and the minimum one of $71.0 \%$ at the $1: 4$ mass ratio of glcerin and sulfuric acid. As the explanation of this result, active component have more attached center in spite of lower porosity.

3) Effects of acid loading on carbide sulfonation reaction. Figure3 shows the effects of acid loading on carbide sulfonation reaction within the range of $1 / 5,2 / 5,3 / 5$, $4 / 5$ and $5 / 5$ under the preparation conditions: the mass ratio of glcerin and sulfuric acid is 1:2, the preparation temperature is $110^{\circ} \mathrm{C}$. The reaction conditions: the molar ratio between gutter oil and methanol is $1: 10$, reaction temperature is $60^{\circ} \mathrm{C}$ and the reaction time is $3 \mathrm{~h}$.

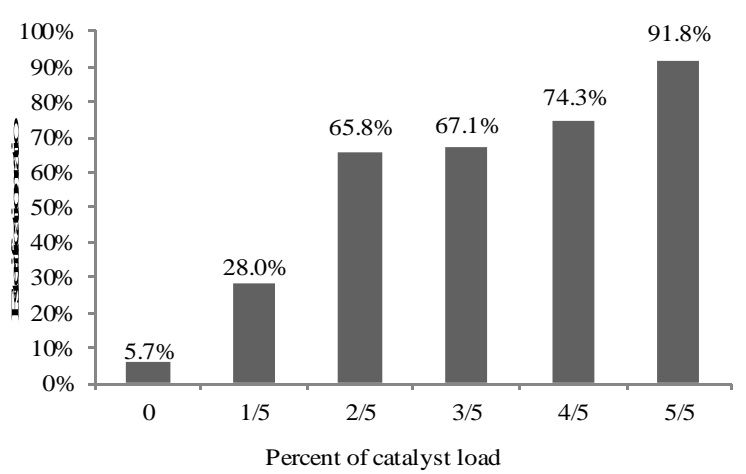

Figure 3. The effects of percent of catalyst load on the esterification reaction ratio

Figure3 shows that the most radical esterification reaction reached to the highest esterification ratio of $91.8 \%$ when the activated carbon gap was completely filled with concentrated sulfuric acid and glycerol.

\section{B. Effects of different reaction conditions}

1) Effects of molar ratio between gutter oil and methanol on esterification reaction. Figure4 shows the effects of molar ratio between gutter oil and methanol on esterification reaction within the range of 1:5, 1:7.5, 1:10, 1:12.5 and 1:15. The preparation conditions are: the mass ratio of glcerin and sulfuric acid is 1:2, the preparation temperature is $110^{\circ} \mathrm{C}$ and the activated carbon is fully filled in the reactor. The reaction conditions are: the reaction temperature is $60^{\circ} \mathrm{C}$ and the reaction time is $3 \mathrm{~h}$.

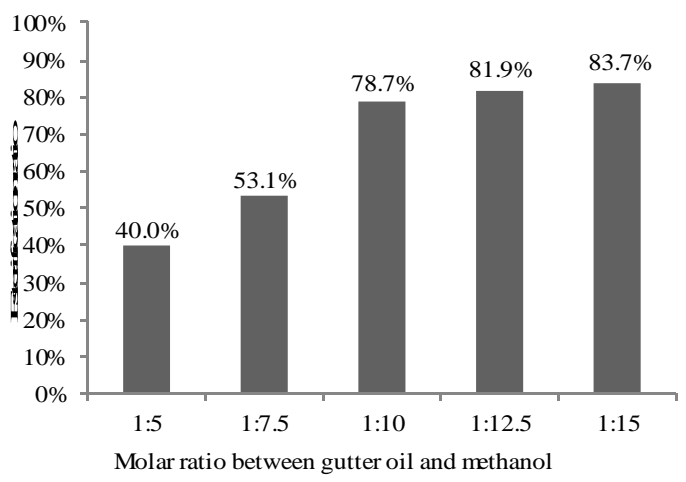

Figure 4. The effects of molar ratio between gutter oil and methanol on the esterification reaction

Figure 4 shows that the optimal molar ratio basis on efficiency and economy between gutter oil and methanol is $1: 12.5$. The ascension of esterification rate is very little in spite of the proliferation of methanol.

2) Effects of reaction temperature on esterification reaction. Figure5 shows the effects of reaction temperature on esterification reaction within the range from $53^{\circ} \mathrm{C}$ to $65^{\circ} \mathrm{C}$ under the preparation conditions: the mass ratio of glcerin and sulfuric acid is $1: 2$, the preparation temperature is $110^{\circ} \mathrm{C}$. The reaction conditions are: the molar ratio between gutter oil and methanol is 1:12.5 and the reaction time is $3 \mathrm{~h}$. 


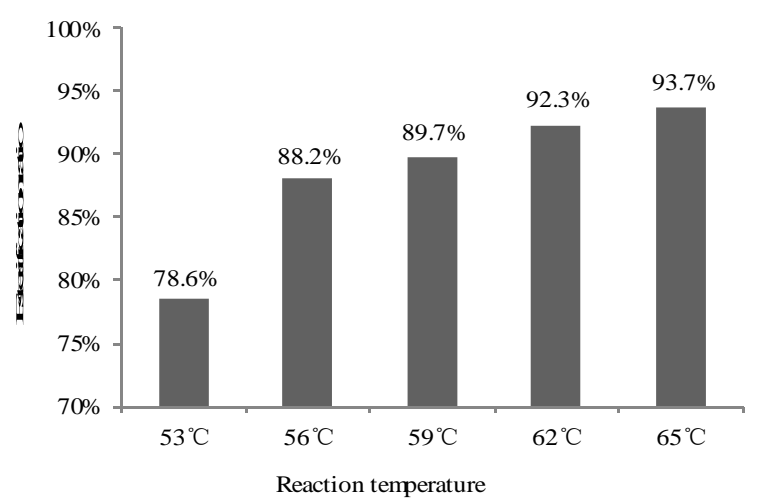

Figure 5. The effects of reaction temperature on the esterification reaction ratio

For the limit of methanol boiling point, the highest reaction temperature was set to $65^{\circ} \mathrm{C}$. Figure 5 shows that with the rising of reaction temperature, the esterification ratio increase and reach to the optimal rate of $93.7 \%$ at $65^{\circ} \mathrm{C}$.

3) Effects of reaction time on esterification reaction. Figure6 shows the effects of reaction time on esterification reaction within the range from $1 \mathrm{~h}$ to $6 \mathrm{~h}$ under the preparation conditions: the mass ratio of glcerin and sulfuric acid is $1: 2$, the preparation temperature is $110^{\circ} \mathrm{C}$. The reaction conditions are: the molar ratio between gutter oil and methanol is $1: 12.5$ and the reaction temperature is $65^{\circ} \mathrm{C}$.

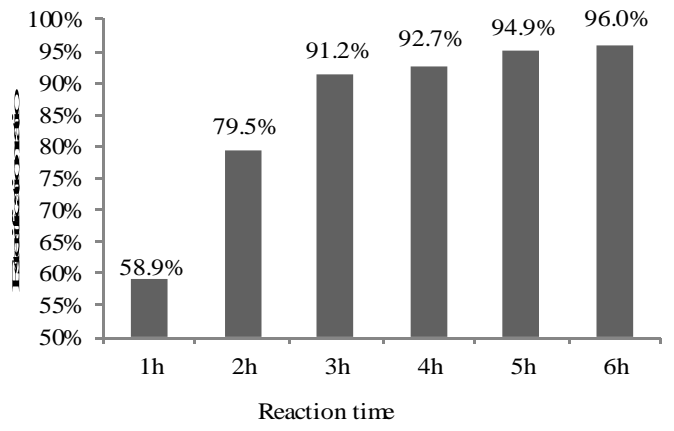

Figure 6. The effects of reaction time on the esterification reaction ratio

Figure6 shows that the esterification rate achieve more value with more reaction time, but increased rarely when reaction time reached $5 \mathrm{~h}$. Considering the energy consumption, the optimum reaction time was selected as $5 \mathrm{~h}$.

\section{Conclusions}

The above experimental data and analysis indicated that the optimal catalyst preparation conditions are: the mass ratio of glcerin and concentrated sulfuric acid is 1:2, activated carbon fully filled and less affected by the preparation temperature condition. The optimal reaction conditions are: molar ratio between gutter oil and methanol is 1:12.5, reacting continuously by 5 hours and the reaction temperature is $65^{\circ} \mathrm{C}$.

\section{ACKNOWLEDGMENT}

This work was financially supported by the Shenzhen Living Environment Committee, Science and Technology Commission of Shen Zhen Municipality (JCYJ20120613154128107, JCYJ20140417172417138).

\section{REFERENCES}

[1] E. Crabbe, C. Nolasco-Hipolito, G. Kobayashi, K. Sakamoto, and A. Ishizaki: Process Biochem, vol. 37, 2001, pp. 65.

[2] F.Ma, and M. A. Hanna, "Biodiesel production: a review," Bioresource technology, 1999, vol. 70 (1), pp. 1-15.

[3] V. Kovacevic, and J. Wesseler, "Cost-effectiveness analysis of algae energy production in the EU," Energy Policy, 2010, vol. 38 (10), pp. 5749-5757.

[4] O. Schrarder, J. Krahl, A. Munack, et al. "Environmental and health effects caused by the use of biodiesel," SAE transactions, 1999, vol. 108 (4), pp. 1756-1766. 